\title{
climate
}

ISSN 2225-1154

www.mdpi.com/journal/climate

Article

\section{Self-Reported Experiences of Climate Change in Nigeria: The Role of Personal and Socio-Environmental Factors}

\author{
Idowu Ajibade *, Frederick Ato Armah, Vincent Kuuire, Isaac Luginaah and Gordon McBean \\ Department of Geography, University of Western Ontario, London, ON N6G 5C2, Canada; \\ E-Mails: farmah@uwo.ca (F.A.); zkuuire@uwo.ca (V.K.); iluginaa@uwo.ca (I.L.); \\ gmcbean@uwo.ca (G.M.)
}

* Author to whom correspondence should be addressed; E-Mail: iajibad@uwo.ca; Tel.: +1-226-378-6407.

Academic Editor: Aondover Tarhule

Received: 14 July 2014 / Accepted: 14 November 2014 /

Published: 23 December 2014

\begin{abstract}
In this study, we examined the individual and socio-environmental factors that mediate differential self-reported experiences of climate change in coastal communities in Lagos, Nigeria. Binary complementary log-log multivariate regression was used to model residents' experiences of changing rainfall patterns, ocean surges, and flood events. An analysis of both compositional and contextual factors showed that there were urban communities where vulnerability to flooding tends to be clustered, and that this was not fully explained by the characteristics of the people of whom the community was composed. This study, thus, underscores the importance and complex nature of the interaction between personal and socio-environmental determinants in shaping climate change experiences and vulnerability of individuals across coastal neighbourhoods. Key findings suggest certain sub-populations as well as geographic clusters in Lagos require special attention from disaster mitigation experts and policy makers.
\end{abstract}

Keywords: climate; perception; floods; rainfall; vulnerability; Lagos 


\section{Introduction}

Climate change impacts are usually exacerbated by a combination of climate stressors (e.g., drought, storms, floods) and other factors, such as socio-environmental conditions, disease outbreaks, environmental degradation over time and other not easily discernible social factors e.g., governance and institutional policy which creates inequalities and tensions over access to resources [1,2]. The impacts of climate change are expected to disproportionately affect coastal areas where population density is high and still increasing [3]. In this context, Africa is considered to be especially vulnerable. For instance, by 2015, three coastal megacities of at least 8 million inhabitants will be located in Africa [4,5]. Climate change is one of the most serious environmental and human threats undermining development and environmental sustainability especially in West Africa where several million people regularly suffer impacts from droughts and floods [6]. Forty percent of the population of West Africa lives in coastal cities, and it is expected that the $500 \mathrm{~km}$ of coastline between Accra and the Niger delta will become a continuous urban megalopolis of more than 50 million inhabitants by 2020 [7]. The probability that sea-level rise could increase flooding, particularly on the coasts of Western Africa is high [8], and may have implications for health [9] particularly diarrhoea, cholera and malaria [10,11].

On the coasts of Western Africa, Nigeria is considered one of the countries whose coastal population is most vulnerable to the biophysical and social impacts of climate change $[11,12]$. Nigeria has a population of 150 million distributed across 36 states consisting of 774 local governments and more than 250 ethnic groups [13]. This heterogeneity suggests that the experience of climate change impacts on the population will be differential across the various geographical regions of the country. Much of Nigeria's densely populated and increasingly urbanized $800-\mathrm{km}$-long southern coast is less than six metres above sea level; the Delta region, with its easily flooded network of estuaries, rivers, creeks, and streams, sits especially low, as does Lagos [14]. The evidence of climate change impacts in Nigeria is quite compelling $[15,16]$. Over the past forty years recorded volumes of torrential rains increased 20 percent across various southern Nigerian states, some of which already experience up to $4000 \mathrm{~mm}$ of rainfall a year, with wet seasons lasting six to eight months [17]. Wheeler [18] found that the homes of 9.7 million Nigerians could be vulnerable to rising seas by 2050. Nigeria's economy relies heavily on climate-sensitive occupations - farming, fishing, and logging which occupy 70 percent of the workforce, contribute over half of GDP, and account for the majority of jobs created recently [19]. According to DFID [20], without a strong response, climate change would cost the country between 6 percent and 30 percent of its GDP by 2050 , worth between $\$ 100$ billion and $\$ 460$ billion.

Climate change has been claimed to have low salience as a risk issue because it cannot be directly experienced $[21,22]$. Being a statistical phenomenon (as climate is defined in terms of average weather) climate is not directly observable [21]. Large random fluctuations of climate variables over time make it less likely for people to precisely detect small climate trends [21]. However, this understanding is debatable because personal factors such as strength of belief in local effects of climatic change have been shown to correlate strongly with responses to climate extremes [23,24] and there is a growing body of literature on the hypothesis that personal experience of climatic hazards (and/or its effects) explains some of those responses [24-26]. Collection of empirical data on personal experiences of climate change is very recent [27], and until now the hypothesis has remained untested. This study is salient because it is one of the first to explore how personal and socio-environmental factors influence self-reported 
experience and perception of climate change by residents of coastal areas. In this paper, we use climate-related events such as rainfall, ocean surges and flooding as proxies for describing respondents' experience of climate change.

Personal and socio-environmental factors have complex influence on perceptions and vulnerability and may as well affect the capacity to adapt to climate change impacts at the individual, household or neighborhood levels [28]. In particular, they may contribute either directly or indirectly to the emergence of social vulnerability through overexploitation of land and resources, environmental degradation, population explosion, and the unequal distribution of wealth and the lack of appropriate public policies. Personal experience of climate change by humans differs in many respects from the occurrence of climate change or climate extremes in the biophysical environment [22]. In fact, there are clear conceptual differences between the two phenomena. Weber [26] distinguishes one from the other and indicates that cognitive processes (e.g., perceptions) are experienced-based while stochastic (probabilistic) processes are description-based. Furthermore, humans and the biophysical environment have entirely different time horizons. The recall bias, of the sort that humans are predisposed to, is not the same for the biophysical environment [29,30]. In humans, memory is rather short even for events (such as floods) that appear to be indelible in the minds of those who have previously encountered it. With time, it fades.

Hitherto, scholars predominantly focused on using time series analyses to model climate change. A few studies have considered how cognitive processes such as climate change perceptions mediate or shape human action. These include experiential learning [31,32], perceptions and realities of indigenous societies [33], psychological barriers to climate change mitigation [34], and the role of cognition and culture in enhancing adaptive capacity [35]. Beyond these, not much attention has been given to self-reported experiences of climate change in urban context in sub-Saharan Africa. Yet, human action is predominantly a function of perception or cognition rather than stochastic considerations [24]. Human action, here, includes coping, adaptation, mitigation, risk aversion, etc. With few exceptions, research on climate change and the vulnerability nexus in Nigeria has disproportionately focused on the biophysical component $[13,17,36]$ and to a limited extent on the social impacts. In the case of the latter, previous researchers have emphasized how climate change could affect individuals and groups of low socio-economic status (i.e., the socially vulnerable). This provides very limited explanation of differential experience of climate impacts among and across people of different socio-economic status. In particular, there is a growing consensus that personal capabilities alone may be inadequate to reduce or reverse current vulnerability trends at the population level, as individuals are embedded within social and physical environments that may also play a significant role in shaping vulnerability [37,38]. What is therefore needed is a focus on a broader range of socio-environmental determinants towards a more complete picture of how and why vulnerability occurs in its current form at the state level in order to push the frontiers of knowledge on how this growing public concern may be addressed. Moreover, the relative importance and interaction between socio-environmental and climatic factors remain to be elucidated in the climate change literature, thus it warrants further investigation. The purpose of this paper is therefore, to contribute to the literature on the relationship between socio-environmental conditions of individuals living in different neighbourhoods and their degree of experience or self-reported observation of climate change, paying special attention to the coastal city of Lagos, Nigeria.

We conceptualise socio-environmental factors as intervening variables between climate change perception and human action. Consistent with [28], we hypothesize that those with fewer resources will 
likely report experience of greater climate change effects, since resources (such as income, information, social network, and technology) may act as a buffer between climate change and its associated impacts. Specifically, social network can make a difference in how individuals perceive and cope with climate change $[39,40]$. This article empirically delineates the feedback relationship between the differential self-reported experiences of climate change by coastal populations and socio-environmental conditions in the Nigerian context. To achieve this objective, the next section presents our theoretical framework followed by the data collection technique, and measures of self-reported experience of climate change and explanatory variables used in this study. The results and discussion provide the relationships between individual and socio-environmental factors, on the one hand, and differential self-reported experience of climate change, on the other hand. Finally, the last section summarizes the main conclusions.

\section{Theoretical Framework}

In simple terms, vulnerability means the propensity to be harmed or affected by a stressor. The predisposition to harm varies geographically, over time, and among different social groups. There are many conceptualizations and applications of vulnerability in different disciplines [41-43]. In hazard and climate change research two broad interpretations of vulnerability stand out. The first interpretation considers vulnerability as an outcome of the net impacts of climate change on a given population or system [44]. This focuses on the end result of exposure and susceptibility to particular climate hazards such as flood and drought, which could lead to loss in crop yield, ecosystem damage or human mortality [45]. The second interpretation considers vulnerability as inherent and as such the focus is less on the end point of climate change impact but rather on underlying socio-economic and institutional factors that give rise to susceptibility to harm, and how these factors change over time and across space [43]. In this formulation, vulnerability is something that exists within a society independent of external hazards. This idea of inherent or contextual vulnerability has evolved from livelihoods [46] political economy [47] and later political ecology approaches $[41,43,48]$. While each of these approaches explores contextual factors that engender differential vulnerability among individuals and groups, their entry points of analysis and interventions differ [49]. A "livelihood" approach, for example, focuses on the need to explore and reassert the building of assets and capabilities at individual, household and community levels [49], whereas the political economy and political ecology approaches draw attention to broader multi-scaled social, economic, political, and environmental factors driving vulnerability at any given time [48]. A major critique of the three approaches is their failure to effectively incorporate perceptions, changing nature and patterns of hazards and how exposure to impacts may change.

Other scholars combine the hazards, livelihood, and political ecology approaches under "social vulnerability framework" to account for individual characteristics, place-based elements, and broader socio-environmental, economic and political factors in determining differential vulnerability between people in different geographic regions. Social vulnerability lays emphasis on social inequalities - specifically social factors that influence or shape the susceptibility of various groups to harm and also constrains their ability to respond. Factors considered in case studies have included gender, age, race, health, income, employment, type of dwelling unit, household composition, resources and information availability, occupancy of high-risk areas, development context, and power-structure in society $[42,50,51]$. These factors tend to intensify the experience of climate change for varying 
populations. In this study, we draw on social vulnerability approach to examine the interaction between individual characteristics and socio-environmental factors in the production of inherent vulnerability to flooding and oceans surges, and further explore how "outcome vulnerability" to future flood hazards may be predicted from the knowledge gained about individuals' perceptions of their inherent vulnerability.

\section{Context and Description of Study Areas}

Lagos is one of the world's megacities at risk from climate change [52,53]. Communities along the coast have been hit hard by floods, storm surges, and rising seas, in part, because of the city's geographic location, topography, inadequate infrastructure, poor urban governance and population congestion. Lagos grew from 252,000 people in 1952 to 11.2 million in 2011, and is predicted to be 18.8 million by 2025, making it the largest urban population in Africa [54]. In recent times, several communities in the city have been exposed to climate-related events but vulnerability to their impacts is unevenly distributed within and across geographic locations. To understand the compositional and contextual factors influencing vulnerability, we selected three different study areas: Victoria Island, Ajah and Ijora Badia (Figure 1). These areas were selected based on their proximity to the Atlantic Ocean and the Lagos lagoon, population size, differential socio-economic status, and availability of risk-reducing infrastructures (such as drainage channels, good roads, and waste-disposal systems).

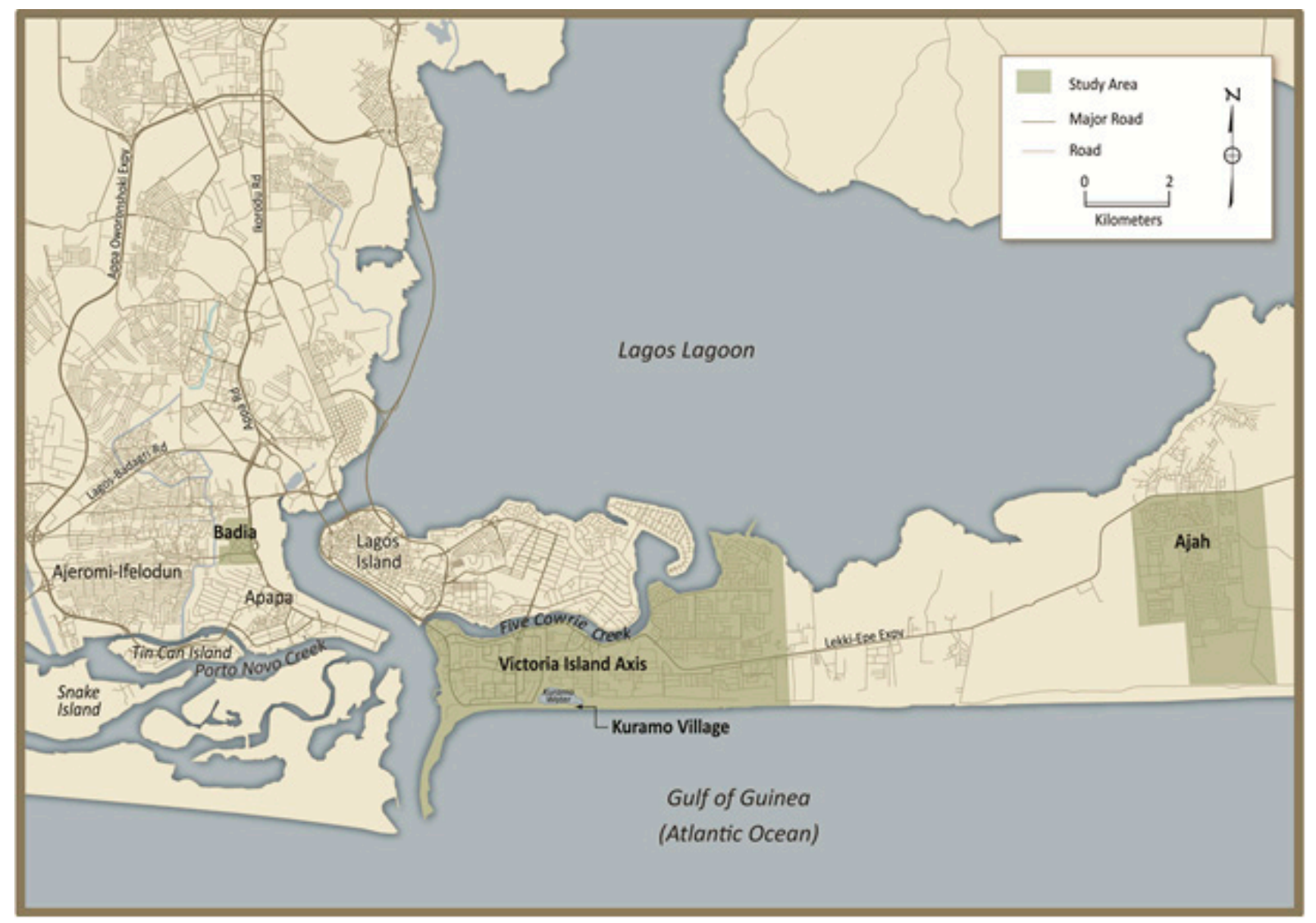

Figure 1. Map of Study Areas. 
Victoria Island, our first study area, is located on the south of Lagos Island close to the Atlantic Ocean. It encompasses Lekki Pennisula and stretches over to the eastern half of Lagos Island to Ikoyi. Ikoyi was originally part of Lagos Island until it was later separated by a narrow waterway dug by the British colonial government who ruled Nigeria between 1900 and 1960. The colonial administration laid the foundation for social and class divide in a spatially visible manner. In no other sector was such division evident than in urban development and planning processes, in that, quality housing, drainage channels, hospitals and modern infrastructures were concentrated in Victoria Island and surrounding areas where the Europeans lived, while the African parts of the city were left to develop haphazardly and were characterised by slum conditions [55]. To date, Victoria Island and its annex in Lekki and Ikoyi are the most affluent neighbourhoods in Lagos mostly occupied by Nigeria's political and economic elites. The estimated population of Victoria Island is about 100,000 people. Major threats to the area are coastal erosion and storm surges. During a storm surge the wave length along the coast which normally range from 0.9 to $2 \mathrm{~m}$ can exceed $4 \mathrm{~m}$, thereby flooding residential spaces and offices [56]. An added effect from sea level rise could mean inundation of the entire Victoria Island-Lekki barrier system and the salinization of both ground and surface water, consequently affecting water quality, commerce, tourism and properties valued at over $\$ 12$ billion [35,57].

The second study site, Ajah, is situated on the eastern end of Victoria Island. It was originally occupied by a small indigenous community of Eti-Osa but has grown to an estimated 60,000 people consisting of a high proportion of middle-income groups and a few high-income groups. Residents in this area face considerable threats from ocean surges and flooding owing in part to their proximity to the ocean and Lagoon. Unlike Ajah and Victoria Island, our third study site, Ijora Badia is a slum located on a swampland in mainland Lagos (Figure 1). The area is a densely populated with over 600,000 residents occupying a total land mass of $1.6 \mathrm{Km}^{2}$ [55]. This community (which includes Abete, Better life, and Badia Central) is characterised by extreme poverty, sub-standard housing, congestion, lack of waste disposal services and poor drainage systems. In the past decade, the community has experienced an increase in vulnerability to flooding which is not solely explained by the changes in rainfall patterns. Human activities - poor land management and alterations to the lagoon environment has allowed for frequent flooding in Ijora Badia.

\section{Materials and Methods}

\subsection{Survey Data Collection and Sampling}

A cross-sectional survey was conducted with 1003 individuals as part of the Coastal Cities at Risk (CCaR) project-Building Adaptive Capacity for Managing Climate Change in Coastal Megacities. The larger project focuses on four cities: Vancouver (Canada), Manila (Philippines), Bangkok (Thailand) and Lagos (Nigeria). However, in this study, individual indicators and socio-environmental determinants for residents from the communities of Ijora Badia, Ajah, and Victoria Island in Lagos, Nigeria were examined. The data was collected between May and November 2011. This study was approved by the Committee of Research Ethics at Western University, Canada. The study population included male and female participants between the ages of 18 and 65 years who were resident in the three communities. The study used multistage sampling to obtain representative estimates of residents in the three communities. 
Based on these communities, 7 neighbourhoods (Badia Central, Better Life, Abete, Ikoyi, Lekki, Ajah and Victoria Island) were randomly sampled with probability proportionate to size of neighbourhood. Sample weights were then assigned to each resident to take into account variations in selection probabilities that occurred during various stages of sampling. The sample size was established assuming: a $95 \%$ confidence interval (CI), a 3.0\% sampling error, and an increment of $10.0 \%$ in order to cover possible lost data. Based on sample size calculations, a total of 900 respondents were required to give the study sufficient power. However, the sample size used for analysis included 1003 subjects, which consisted of 453 females and 550 males.

\subsection{Multivariate Regression}

The data were analyzed using the IBM Statistical Package for the Social Sciences (IBM SPSS, version 20.0). The impacts of social and environmental determinants on residents' experience of climate change were analyzed by using odds ratios (ORs), established by binary complementary log-log regression adjusted for the remaining independent variables included in the regression models. OR $=1$ implies that exposure does not affect odds of outcome; OR $>1$ implies that predictor is associated with higher odds of outcome; and OR $<1$ implies that predictor is associated with lower odds of outcome. Only social and environmental predictors that presented a level of significance $\leq 0.20$ for association with the experience of climate change in the $x^{2}$ test were included in the complementary log-log regression model. All analyses were performed for the whole sample considering the clustering effect. Two sets of theoretically relevant factors: compositional (personal and household) and contextual (socio-environmental) are important [58] in understanding perception and experience of climate change. This informed our decision to select a range of compositional variables including age, gender, highest educational attainment, marital status, position in household, household size and composition, ethnicity, occupation, income levels and length of stay in current home and the neighbourhood. We also accounted for contextual variables such as residential neighbourhood, type of housing, vulnerability of dwelling and neighbourhood to flooding, social assistance due to flooding, and access to health and water services.

Three main outcome variables that reflect differential experiences of climate change were analyzed: observations of changes in rainfall patterns over the last 10 years; experiences of ocean surges; and experiences of flooding. All outcome variables were dichotomous. The three variables examined whether respondents have observed: changes in rainfall patterns or not, coded as (no $=0$, yes $=1$ ); experienced surges in the oceans or not, coded as (no $=0$, yes $=1)$; and experienced flooding or not, also coded as $($ no $=0$, yes $=1)$. Under the assumption of binary response, there are three potential alternatives: the logit model, probit model and complementary log-log model. Both logit and probit links have the same property, which is link $[\pi(x)]=\log [-\log (1-\pi(x))]$.

This means that the response curve for $\pi(\mathrm{x})$ has a symmetric appearance about the point $\pi(x)=0.5$ and so $\pi(x)$ has the same rate for approaching 0 as well as for approaching 1 . In this study, none of the outcome variables satisfied this property of symmetry. When the responses are asymmetric in the $(0,1)$ interval, and increase slowly at small to moderate value but increases sharply near 1 , as in the case of the three outcome variables in this study, a complementary log-log link function is appropriate. In this study, observation of changing rainfall patterns $(25 \%, 75 \%)$, experience of ocean surges $(80 \%, 20 \%)$ and experience of flooding $(13 \%, 87 \%)$ exhibit asymmetry. Therefore logit and probit models that rely 
on $(50 \%, 50 \%)$ curves were considered inappropriate for modelling them. The complementary log-log model gives a better representation and was therefore used for the analysis of the three outcome variables.

\section{Results}

\subsection{Descriptive Statistics}

Table 1 shows the summary statistics of the outcome and explanatory variables used in this study. Almost $74 \%$ of respondents were married. About $61 \%$ of respondents were from Ijora Badia (poorest community). A large number ( $80 \%$ ) of respondents did not own their current dwelling. About $60 \%$ of respondents had lived in their communities for 5 years or more. Approximately $60 \%$ and $80 \%$ of respondents, respectively, indicated that their current dwelling and residential neighbourhood were prone to flooding. Most respondents indicated that they had never received social assistance from government as a result of flooding (92\%), had no access to social housing (91\%), and had to walk more than $5 \mathrm{~km}$ to access public healthcare services (73\%). Cross tabulating using chi-square indicates that statistically significant differences exist between males and females in terms of observation of changes in rainfall patterns. However, there were no gender differences regarding their reported experiences of both ocean surges and flooding. Statistically significant differences exist among the various age groups in terms of their reported experiences of the three outcome measures (rainfall, flood and ocean surge).

Table 1. Descriptive statistics of outcome and explanatory variables $(n=1003)$.

\begin{tabular}{ccc}
\hline Outcome Variables & Frequency & $\mathbf{\%}$ \\
\hline Noticed Changes in Rainfall Patterns in last 10 years & & \\
\hline No & 252 & 25.1 \\
Yes & 751 & 74.9 \\
\hline Experience of Ocean Surge in the last 5 years & & \\
\hline No & 804 & 80.2 \\
Yes & 199 & 19.8 \\
\hline Experience of Flooding in the last 5 years & & \\
\hline No & 126 & 12.6 \\
Yes & 877 & 87.4 \\
\hline Explanatory Variables & & \\
\hline Personal \& Household Factors & & \\
\hline Age & 209 & 20.8 \\
18-30 & 622 & 62.0 \\
31-40 & 172 & 17.2 \\
41-65 & \\
\hline Gender & 453 & 45.2 \\
Female & 550 & 54.8 \\
\hline Male & 348 & 34.7 \\
\hline Up to Primary & 388 & 38.7 \\
Secondary & 267 & 26.6 \\
\hline Tertiary & &
\end{tabular}


Table 1. Cont.

\begin{tabular}{|c|c|c|}
\hline Outcome Variables & Frequency & $\%$ \\
\hline \multicolumn{3}{|l|}{ Marital Status } \\
\hline Unmarried & 257 & 25.6 \\
\hline Married & 746 & 74.4 \\
\hline \multicolumn{3}{|l|}{ Position in Household } \\
\hline Head & 547 & 54.5 \\
\hline Non-head & 456 & 45.5 \\
\hline \multicolumn{3}{|l|}{ Household Size } \\
\hline 1 to 3 & 252 & 25.1 \\
\hline 4 or 5 & 506 & 50.5 \\
\hline 6 or more & 245 & 24.4 \\
\hline \multicolumn{3}{|l|}{ Ethnicity } \\
\hline Yoruba & 628 & 62.6 \\
\hline Ibo & 325 & 32.4 \\
\hline Hausa & 23 & 2.3 \\
\hline Other & 27 & 2.7 \\
\hline \multicolumn{3}{|l|}{ Occupation } \\
\hline Unemployed & 105 & 10.5 \\
\hline Civil servant & 163 & 16.3 \\
\hline Artisan & 189 & 18.8 \\
\hline self-employed & 546 & 54.4 \\
\hline \multicolumn{3}{|l|}{ Household Income Levels } \\
\hline $\mathrm{N} 5,000-\mathrm{N} 15,000$ & 186 & 18.5 \\
\hline $\mathrm{N} 15,500-\mathrm{N} 25,000$ & 232 & 23.1 \\
\hline $\mathrm{N} 25,500-\mathrm{N} 50,000$ & 207 & 20.6 \\
\hline N50,500 and above & 97 & 9.7 \\
\hline will rather not say & 281 & 28.0 \\
\hline \multicolumn{3}{|c|}{ Length of stay in Community } \\
\hline less than 5 years & 399 & 39.8 \\
\hline $5+$ years & 604 & 60.2 \\
\hline \multicolumn{3}{|c|}{ Length of stay in present dwelling } \\
\hline less than 5 years & 432 & 43.1 \\
\hline $5+$ years & 571 & 56.9 \\
\hline \multicolumn{3}{|l|}{ Dwelling ownership } \\
\hline Owner & 205 & 20.4 \\
\hline Renters & 798 & 79.6 \\
\hline \multicolumn{3}{|c|}{ Socio-Environmental Factors } \\
\hline \multicolumn{3}{|l|}{ Location } \\
\hline Ijora Badia & 607 & 60.5 \\
\hline Ajah & 120 & 12.0 \\
\hline Victoria Island & 276 & 27.5 \\
\hline \multicolumn{3}{|l|}{ Type of housing } \\
\hline wooden shack & 181 & 18.1 \\
\hline wooden on stilts & 191 & 19.0 \\
\hline Concrete & 631 & 62.9 \\
\hline
\end{tabular}


Table 1. Cont.

\begin{tabular}{ccc}
\hline Outcome Variables & Frequency & $\%$ \\
\hline Vulnerability of housing type to flood events & & \\
\hline No & 228 & 22.7 \\
Yes & 603 & 60.1 \\
Refused to answer & 172 & 17.2 \\
\hline Vulnerability of neighbourhood to flood events & & \\
\hline No & 131 & 13.1 \\
Yes & 810 & 80.8 \\
Refused to answer & 62 & 6.2 \\
\hline Ever received government assistance due to flooding & & \\
\hline No & 926 & 92.3 \\
Yes & 77 & 7.7 \\
\hline Access to social housing & 913 & 91.0 \\
No & 90 & 9.0 \\
\hline Yes & \\
\hline Access to water services & 569 & 56.7 \\
poor water access & 434 & 43.3 \\
\hline good water access & 72.8 \\
\hline Less than 5 km & 730 & 27.2 \\
\hline
\end{tabular}

\subsection{Bivariate Analysis}

Concerning changing rainfall patterns, some interesting results were obtained when we compared the bivariate results (tables not reported) with the multivariate analysis. Neighborhood vulnerability to flood and distance to health care facility which were not significant predictors of perceived changing rainfall patterns became significant at the multivariate level. On the other hand, length of stay in area and access to water services lost significance at the multivariate level. In terms of ocean surges, marital status which was not a significant predictor of self-reported experience of ocean surges at the bivariate level became significant in the multivariate model. However, the relationship between self-reported experience of ocean surges and age, position in household, occupation, length of stay in area, type of housing and government assistance due to flood, disappeared at the multivariate level. The relationship between experience of flood and gender, education, number of people in household, length of dwelling and distance to health facility at the bivariate level was not robust and disappeared in the multivariate analysis. Nevertheless, regarding the experience of flood, marital status which was not significant at the bivariate level became significant at the multivariate level.

\subsection{Multivariate Analysis}

Table 2 shows the multivariate relationship between individual, household level and socio-environmental factors on the one hand, and respondents' experiences of changing rainfall patterns on the other hand. In model 1, which accounts for individual and household level determinants, individuals in the 31-40 age 
group were more likely $(\mathrm{OR}=1.41, p \leq 0.05)$ to report having experienced changing rainfall patterns compared to those in the 18-30 age group. Similarly, individuals in the 41-65 age group were more likely $(\mathrm{OR}=2.65, p \leq 0.001)$ to report having experienced changing rainfall patterns compared to those in the 18-30 age group. Length of stay in the community and gender were not significant predictors of respondents' reported experiences of changing rainfall patterns unlike length of stay in current dwelling. Surprisingly, individuals who had lived for 5 years or more $(\mathrm{OR}=0.34, p \leq 0.001)$ in their present dwelling were less likely to report observed changes in rainfall patterns compared to their counterparts who had lived in their present dwelling for less than 5 years. Individuals who had attained secondary education $(\mathrm{OR}=0.59, p \leq 0.001)$ and those who had attained tertiary education $(\mathrm{OR}=0.73, p \leq 0.05)$ were less likely to report having experienced changes in rainfall patterns compared to their counterparts who were educated up to primary level. Married individuals were less likely $(\mathrm{OR}=0.72, p \leq 0.05)$ to report having experienced changes in rainfall patterns compared to unmarried individuals. Non-household heads were less likely ( $\mathrm{OR}=0.64, p \leq 0.01)$ to report having experienced changing patterns in rainfall compared to household heads. Artisans were less likely to report having experienced changing patterns in rainfall compared to their unemployed counterparts. Furthermore, individuals who had monthly incomes between 15,500 and 25,000 Naira (up to 160 USD) were more likely to report having experienced changes in rainfall patterns compared to their counterparts in the lowest income group (up to 95 USD). However, individuals who had monthly income between 25,500 and 50,000 Naira (up to 325 USD) were less likely ( $\mathrm{OR}=0.58, p \leq 0.01$ ) to report having experienced changes in rainfall patterns compared to those in the lowest income group. Similarly, Individuals who had monthly income of 50,500 Naira or more ( $>400 \mathrm{USD})$ were less likely $(\mathrm{OR}=0.59, p \leq 0.05)$ to report having experienced changes in rainfall patterns compared to their counterparts in the lowest income group. Individuals of the Hausa ethnic group were less likely to report having experienced changing patterns in rainfall compared to their Yoruba counterparts. Households comprising of 4 or more individuals were more likely to report having experienced changing patterns in rainfall compared to households consisting of 1 to 3 individuals.

Table 2. Multivariate complementary log-log regression model predicting the experience of changing rainfall patterns by coastal communities in Lagos, Nigeria.

\begin{tabular}{|c|c|c|c|c|c|c|}
\hline \multirow[b]{2}{*}{ Variables } & \multicolumn{3}{|c|}{$\begin{array}{l}\text { Model 1: Personal \& } \\
\text { Household Factors }\end{array}$} & \multicolumn{3}{|c|}{$\begin{array}{l}\text { Model 2: Socio-Environmental } \\
\text { Factors }\end{array}$} \\
\hline & OR & (Robust SE) & $95 \% \mathrm{CI}$ & OR & (Robust SE) & $95 \% \mathrm{CI}$ \\
\hline \multicolumn{7}{|c|}{ Age (ref: 18-30) } \\
\hline $31-40$ & 1.41 & $(0.21) *$ & $1.05-1.90$ & 1.73 & $(0.30) * *$ & $1.23-2.43$ \\
\hline $41-65$ & 2.65 & $(0.54) * * *$ & $1.77-3.96$ & 3.42 & $(0.92) * * *$ & $2.03-5.79$ \\
\hline \multicolumn{7}{|c|}{ Gender (ref: female) } \\
\hline Male & 1.01 & $(0.14)$ & $0.78-1.31$ & 0.99 & $(0.15)$ & $0.73-1.34$ \\
\hline \multicolumn{7}{|c|}{ Respondent Education (ref: up to primary) } \\
\hline Secondary & 0.59 & $(0.07) * * *$ & $0.47-0.73$ & 0.57 & $(0.08) * * *$ & $0.44-0.75$ \\
\hline Tertiary & 0.73 & $(0.12) *$ & $0.53-0.99$ & 0.69 & $(0.15)$ & $0.46-1.06$ \\
\hline \multicolumn{7}{|c|}{ Marital Status (ref: Unmarried) } \\
\hline Married & 0.72 & $(0.10) *$ & $0.55-0.95$ & 0.75 & $(0.11)$ & $0.56-1.01$ \\
\hline
\end{tabular}


Table 2. Cont.

\begin{tabular}{|c|c|c|c|c|c|c|}
\hline \multirow[b]{2}{*}{ Variables } & \multicolumn{3}{|c|}{$\begin{array}{c}\text { Model 1: Personal \& } \\
\text { Household Factors }\end{array}$} & \multicolumn{3}{|c|}{$\begin{array}{l}\text { Model 2: Socio-Environmental } \\
\text { Factors }\end{array}$} \\
\hline & OR & (Robust SE) & $95 \%$ CI & OR & (Robust SE) & $95 \% \mathrm{CI}$ \\
\hline \multicolumn{7}{|c|}{ Position in Household (ref: Head) } \\
\hline Non-head & 0.64 & $(0.09) * *$ & $0.49-0.83$ & 0.71 & $(0.11) *$ & $0.53-0.95$ \\
\hline \multicolumn{7}{|c|}{ No. People in Household (ref: 1-3) } \\
\hline 4 or 5 & 1.75 & $(0.23) * * *$ & $1.34-2.27$ & 1.55 & $(0.24) * *$ & $1.15-2.09$ \\
\hline 6 or more & 1.49 & $(0.22) * *$ & $1.12-1.97$ & 1.61 & $(0.26) * *$ & $1.17-2.22$ \\
\hline \multicolumn{7}{|c|}{ Ethnicity (ref: Yoruba) } \\
\hline Ibo & 0.99 & $(0.11)$ & $0.79-1.23$ & 1.00 & $(0.15)$ & $0.75-1.33$ \\
\hline Hausa & 0.41 & $(0.13) * *$ & $0.21-0.77$ & 0.40 & $(0.15) *$ & $0.19-0.84$ \\
\hline Other & 1.00 & $(0.30)$ & $0.56-1.78$ & 1.11 & $(0.34)$ & $0.60-2.03$ \\
\hline \multicolumn{7}{|c|}{ Occupation (ref: unemployed) } \\
\hline Civil servant & 1.54 & $(0.32) *$ & $1.02-2.32$ & 1.28 & $(0.34)$ & $0.75-2.17$ \\
\hline Artisan & 0.39 & $(0.08) * * *$ & $0.26-0.59$ & 0.35 & $(0.09) * * *$ & $0.21-0.58$ \\
\hline self-employed & 0.91 & $(0.16)$ & $0.64-1.29$ & 0.78 & $(0.17)$ & $0.51-1.19$ \\
\hline \multicolumn{7}{|c|}{ Household Income (ref: N5,000-N15,000) } \\
\hline $\mathrm{N} 15,500-\mathrm{N} 25,000$ & 1.80 & $(0.29) * * *$ & $1.30-2.48$ & 1.36 & $(0.26)$ & $0.94-1.97$ \\
\hline $\mathrm{N} 25,500-\mathrm{N} 50,000$ & 0.58 & $(0.10) * *$ & $0.42-0.80$ & 0.43 & $(0.08) * * *$ & $0.30-0.62$ \\
\hline N50,500- or more & 0.59 & $(0.12) *$ & $0.39-0.88$ & 0.60 & $(0.15)$ & $0.37-0.97$ \\
\hline will rather not say & 1.06 & $(0.15)$ & $0.80-1.40$ & 0.78 & $(0.13)$ & $0.56-1.07$ \\
\hline \multicolumn{7}{|c|}{ Length of stay in area (ref: less than 5 years) } \\
\hline 5 years or more & 1.08 & $(0.29)$ & $0.63-1.84$ & 1.54 & $(0.43)$ & $0.89-2.66$ \\
\hline \multicolumn{7}{|c|}{ Length of stay in dwelling (ref: less than 5 years) } \\
\hline 5 years or more & 0.34 & $(0.09) * * *$ & $0.20-0.58$ & 0.27 & $(0.08) * * *$ & $0.15-0.47$ \\
\hline \multicolumn{7}{|c|}{ Dwelling ownership (ref: owner) } \\
\hline Renters & 0.75 & $(0.09) *$ & $0.59-0.96$ & 0.85 & $(0.14)$ & $0.62-1.16$ \\
\hline \multicolumn{7}{|c|}{ Location (ref: Ijora Badia) } \\
\hline Ajah & & & & 23.86 & $(5.28) * * *$ & $15.47-36.81$ \\
\hline Victoria Island & & & & 1.12 & $(0.23)$ & $0.75-1.67$ \\
\hline \multicolumn{7}{|c|}{ Type of housing (ref: wooden shack) } \\
\hline wooden on stilts & & & & 1.82 & $(0.36) * *$ & $1.24-2.68$ \\
\hline Concrete & & & & 1.07 & $(0.18)$ & $0.77-1.48$ \\
\hline \multicolumn{7}{|c|}{ Household vulnerability to flood (ref: no) } \\
\hline Yes & & & & 1.40 & $(0.25)$ & $0.99-2.00$ \\
\hline Refused to answer & & & & 2.89 & $(0.77) * * *$ & $1.71-4.86$ \\
\hline \multicolumn{7}{|c|}{ Neighbourhood vulnerability to flood (ref: no) } \\
\hline Yes & & & & 0.75 & $(0.14)$ & $0.53-1.08$ \\
\hline Don't know & & & & 0.32 & $(0.09) * * *$ & $0.18-0.55$ \\
\hline \multicolumn{7}{|c|}{ Ever received government assistance due to flood (ref: no) } \\
\hline Yes & & & & 1.18 & $(0.27)$ & $0.75-1.86$ \\
\hline \multicolumn{7}{|c|}{ Access to social housing (ref: no) } \\
\hline Yes & & & & 1.40 & $(0.28)$ & $0.94-2.07$ \\
\hline \multicolumn{7}{|c|}{ Access to water services (ref: poor) } \\
\hline good water access & & & & 0.99 & $(0.12)$ & $0.78-1.26$ \\
\hline \multicolumn{7}{|c|}{ Distance to nearest healthcare facility (ref: $5 \mathrm{~km}$ or more) } \\
\hline Less than $5 \mathrm{~km}$ & & & & 0.64 & $(0.09) * *$ & $0.49-0.85$ \\
\hline
\end{tabular}


Model 2 accounts for socio-environmental determinants. The excess odds, of the 31-40 age groups, increased by $23 \%$ from 1.41 to 1.73 . Also, the excess odds of the $41-65$ age group increased by $29 \%$ from 2.65 to 3.42 . Gender and length of stay in the community were still not significant predictors of reported experience of changing rainfall patterns. Tertiary educational attainment, home ownership and marital status became insignificant predictors of reported experience of changing rainfall patterns when socio-environmental variables were accounted for. In the Nigerian context, people who have attained tertiary education probably engage in formal sector employment, which does not expose them to the vagaries of the weather. The odds ratios of position in household and household composition remained practically the same although the strength of income became reduced when socio-environmental variables were accounted for. Residents in Ajah (a richer neighbourhood) were more likely ( $\mathrm{OR}=23.86$, $p \leq 0.001)$ to report having experienced changes in rainfall patterns compared to residents in Ijora Badia (the poorest community). Individuals who live in wooden houses on stilts were more likely $(\mathrm{OR}=1.82$, $p \leq 0.01)$ to report having experienced changes in rainfall patterns compared to residents who live in shacks on ground. Respondents who refused to answer whether their dwelling was susceptible to flooding were more likely to report having experienced changing rainfall patterns compared to those who reported that their household was not prone to flooding. A disproportionate number of the former were residents in Ijora Badia (poorest/slum community). Anecdotal evidence suggests such residents prefer to remain silent on flood issues for fear of forcible eviction by government officials. This is because local development authorities attribute the incidence of flooding to the proliferation of slums warranting eviction [55]. Access to water services and social support from government was, however, not a significant predictor of the experience of changing patterns in rainfall.

Table 3 shows the multivariate relationship between respondents' experiences of ocean surges on the one hand, and individual, household level, and social environmental factors on the other hand. In model 1, gender, position in household and occupation were not significant predictors of reported experiences of ocean surges by respondents. Also, length of stay in the community and length of stay in current dwelling were not significant predictors either. However, age, marital status, education, household size, income and home ownership were significant predictors. Individuals in the 31-40 age group were more likely $(\mathrm{OR}=2.63, p \leq 0.001)$ to have experienced ocean surges compared to those in the 18-30 age group. Similarly, individuals in the 41-65 age group were more likely $(\mathrm{OR}=1.97, p \leq 0.05)$ to have experienced ocean surges compared to those in the 18-30 age group. Married individuals were less likely $(\mathrm{OR}=0.43$, $p \leq 0.001)$ to report having experienced ocean surges compared to their unmarried counterparts. Households comprising of 4 and 5 individuals were more likely ( $\mathrm{OR}=2.07, p \leq 0.01)$ to report having experienced ocean surges compared to households comprising of 1 to 3 individuals. Also, households consisting of 6 or more individuals were more likely ( $\mathrm{OR}=2.92, p \leq 0.001)$ to have experienced ocean surges compared to households comprising of less than 3 individuals. Individuals who had monthly incomes between 15,500 and 25,000 Naira (up to $160 \mathrm{USD}$ ) were less likely (OR $=0.05, p \leq 0.001$ ) to have experienced ocean surges compared to those in the lowest income group. However, respondents who had monthly income between 25,500 and 50,000 Naira (up to 325 USD) were more likely $(\mathrm{OR}=1.99, p \leq 0.05)$ to report that they had experienced ocean surges compared to those in the lowest income group. Most of such residents reside in Ajah and Victoria Island, which is not far from the Atlantic Ocean. Interestingly, those who refused to disclose their monthly income were more likely $(\mathrm{OR}=4.42, p \leq 0.001)$ to report that they had experienced ocean surges compared to those in the lowest 
income group. Renters were more likely $(\mathrm{OR}=2.85, p \leq 0.001)$ to report that they had experienced ocean surges compared to home owners.

Table 3. Multivariate complementary log-log regression model predicting the experience of ocean surges by coastal communities in Lagos.

\begin{tabular}{|c|c|c|c|c|c|c|}
\hline \multirow[t]{2}{*}{ Variables } & \multicolumn{3}{|c|}{$\begin{array}{c}\text { Model 1: Personal \& Household } \\
\text { Factors } \\
\end{array}$} & \multicolumn{3}{|c|}{$\begin{array}{c}\text { Model 2: Socio-Environmental } \\
\text { Factors }\end{array}$} \\
\hline & OR & (Robust SE) & $95 \% \mathrm{CI}$ & OR & (Robust SE) & $95 \% \mathrm{CI}$ \\
\hline \multicolumn{7}{|c|}{ Age (ref: $18-30)$} \\
\hline $31-40$ & 2.63 & $(0.59) * * *$ & $1.69-4.08$ & 1.63 & $(0.50)$ & $0.89-2.99$ \\
\hline $41-65$ & 1.97 & $(0.61) *$ & $1.08-3.61$ & 1.28 & $(0.53)$ & $0.57-2.88$ \\
\hline \multicolumn{7}{|c|}{ Gender (ref: female) } \\
\hline Male & 1.06 & $(0.22)$ & $0.70-1.59$ & 0.63 & $(0.17)$ & $0.37-1.09$ \\
\hline \multicolumn{7}{|c|}{ Respondent Education (ref: up to primary) } \\
\hline Secondary & 0.29 & $(0.06) * * *$ & $0.19-0.44$ & 0.24 & $(0.06) * * *$ & $0.14-0.40$ \\
\hline Tertiary & 1.07 & $(0.27)$ & $0.65-1.76$ & 0.34 & $(0.14) *$ & $0.15-0.77$ \\
\hline \multicolumn{7}{|c|}{ Marital Status (ref: Unmarried) } \\
\hline Married & 0.43 & $(0.10) * * *$ & $0.27-0.68$ & 0.44 & $(0.11) * *$ & $0.27-0.71$ \\
\hline \multicolumn{7}{|c|}{ Position in Household (ref: Head) } \\
\hline Non-head & 0.90 & $(0.20)$ & $0.57-1.40$ & 1.00 & $(0.28)$ & $0.57-1.73$ \\
\hline \multicolumn{7}{|c|}{ No. People in Household (ref: 1-3) } \\
\hline 4 or 5 & 2.07 & $(0.55) * *$ & $1.23-3.50$ & 1.89 & $(0.54) *$ & $1.08-3.31$ \\
\hline 6 or more & 2.92 & $(0.76) * * *$ & $1.75-4.86$ & 2.01 & $(0.64) *$ & $1.08-3.75$ \\
\hline \multicolumn{7}{|c|}{ Ethnicity (ref: Yoruba) } \\
\hline Ibo & 0.65 & $(0.14) *$ & $0.43-0.98$ & 0.93 & $(0.22)$ & $0.59-1.47$ \\
\hline Hausa & 0.93 & $(0.39)$ & $0.41-2.13$ & 1.54 & $(0.66)$ & $0.66-3.59$ \\
\hline Other & 0.50 & $(0.31)$ & $0.15-1.68$ & 0.58 & $(0.34)$ & $0.18-1.85$ \\
\hline \multicolumn{7}{|c|}{ Occupation (ref: unemployed) } \\
\hline Civil servant & 2.00 & $(0.76)$ & $0.95-4.19$ & 2.77 & $(1.62)$ & $0.88-8.69$ \\
\hline Artisan & 1.51 & $(0.56)$ & $0.73-3.12$ & 2.19 & $(1.28)$ & $0.70-6.86$ \\
\hline self-employed & 0.86 & $(0.29)$ & $0.44-1.68$ & 1.80 & $(0.96)$ & $0.63-5.13$ \\
\hline \multicolumn{7}{|c|}{ Household Income (ref: N5,000-N15,000) } \\
\hline $\mathrm{N} 15,500-\mathrm{N} 25,000$ & 0.05 & $(0.04) * * *$ & $0.01-0.25$ & 0.09 & $(0.08) * *$ & $0.02-0.51$ \\
\hline $\mathrm{N} 25,500-\mathrm{N} 50,000$ & 1.99 & $(0.69) *$ & $1.01-3.93$ & 0.87 & $(0.35)$ & $0.39-1.91$ \\
\hline N50,500- or more & 1.00 & $(0.41)$ & $0.45-2.26$ & 0.86 & $(0.43)$ & $0.32-2.29$ \\
\hline will rather not say & 4.42 & $(1.32) * * *$ & $2.46-7.95$ & 3.46 & $(1.18) * * *$ & $1.78-6.74$ \\
\hline \multicolumn{7}{|c|}{ Length of stay in area (ref: less than 5 years) } \\
\hline 5 years or more & 1.06 & $(0.36)$ & $0.55-2.05$ & 1.54 & $(0.57)$ & $0.74-3.19$ \\
\hline \multicolumn{7}{|c|}{ Length of stay in dwelling (ref: less than 5 years) } \\
\hline 5 years or more & 0.57 & $(0.20)$ & $0.29-1.12$ & 0.32 & $(0.11) * *$ & $0.16-0.63$ \\
\hline \multicolumn{7}{|c|}{ Dwelling ownership (ref: owner) } \\
\hline Renters & 2.85 & $(0.77) * * *$ & $1.68-4.85$ & 1.61 & $(0.47)$ & $0.91-2.84$ \\
\hline \multicolumn{7}{|c|}{ Location (ref: Ijora Badia) } \\
\hline Ajah & & & & 19.82 & $(8.87) * * *$ & $8.24-47.62$ \\
\hline Victoria Island & & & & 3.54 & $(1.09) * * *$ & $1.94-6.46$ \\
\hline
\end{tabular}


Table 3. Cont.

\begin{tabular}{|c|c|c|c|c|}
\hline \multirow[t]{2}{*}{ Variables } & $\begin{array}{l}\text { Model 1: Personal \& Household } \\
\text { Factors }\end{array}$ & \multicolumn{3}{|c|}{$\begin{array}{l}\text { Model 2: Socio-Environmental } \\
\text { Factors }\end{array}$} \\
\hline & (Robust SE) & OR & (Robust SE) & \\
\hline \multicolumn{5}{|c|}{ Type of housing (ref: wooden shack) } \\
\hline wooden on stilts & & 1.02 & $(0.42)$ & $0.45-2.28$ \\
\hline Concrete & & 1.79 & $(0.67)$ & $0.87-3.71$ \\
\hline \multicolumn{5}{|c|}{ Household vulnerability to flood (ref: no) } \\
\hline Yes & & 2.07 & $(0.67) *$ & $1.09-3.92$ \\
\hline Refused to answer & & 0.14 & $(0.14) *$ & $0.02-0.96$ \\
\hline \multicolumn{5}{|c|}{ Neighbourhood vulnerability to flood (ref: no) } \\
\hline Yes & & 3.42 & $(1.42) * *$ & $1.52-7.73$ \\
\hline Don't know & & 1.90 & $(1.22)$ & $0.54-6.67$ \\
\hline \multicolumn{5}{|c|}{ Ever received government assistance due to flood (ref: no) } \\
\hline Yes & & 0.99 & $(0.34)$ & $0.50-1.95$ \\
\hline \multicolumn{5}{|c|}{ Access to social housing (ref: no) } \\
\hline Yes & & 1.33 & $(0.46)$ & $0.67-2.63$ \\
\hline \multicolumn{5}{|c|}{ Access to water services (ref: poor) } \\
\hline good water access & & 0.46 & $(0.13) * *$ & $0.27-0.79$ \\
\hline \multicolumn{5}{|c|}{ Distance to nearest healthcare facility (ref: $5 \mathrm{~km}$ or more) } \\
\hline Less than $5 \mathrm{~km}$ & & 0.11 & $(0.05) * * *$ & $0.05-0.25$ \\
\hline
\end{tabular}

In model 2, dwelling ownership lost significance whereas length of stay in current dwelling became significant when socio-environmental factors were accounted for. The 325USD income group was no longer a predictor of respondents' experiences of ocean surges in this model. The excess odds for households composed of 4 and 5 individuals reduced by $18 \%$ from 2.07 to 1.89 . The excess odds for households composed of 6 or more individuals also reduced by $47 \%$ from 2.92 to 2.01 . Individuals resident in Ajah and Victoria Island were more likely to report that they had experienced ocean surges compared to residents of Ijora Badia (poorest community). The proximity of these two latter areas to the Atlantic Ocean accounts for this observation. Respondents who had access to good water services were less likely to report that they had experienced ocean surges compared to individuals who had poor access to water services. Those who live less than $5 \mathrm{~km}$ from the nearest health facility were less likely $(\mathrm{OR}=0.11, p \leq 0.001)$ to report that they had experienced ocean surges compared to those who live $5 \mathrm{~km}$ or more from the nearest health facility. Respondents who indicated that their households were vulnerable to flooding were more likely $(\mathrm{OR}=2.07, p \leq 0.05)$ to report that they had experienced ocean surges compared to those who answered no. Similarly, respondents who indicated that their neighbourhoods were vulnerable to flooding were more likely $(\mathrm{OR}=3.42, p \leq 0.01)$ to have experienced ocean surges compared to those who answered no.

Table 4 shows the multivariate relationship between individual and household level factors and socio-environmental factors on the one hand, and respondents' experiences of flooding on the other hand. In model 1, age, gender, marital status, position in household, household composition, and occupation were not significant predictors of respondents' reported experience of flooding. Unexpectedly, age, length of 
stay in current dwelling and length of stay in neighbourhood were also not significant predictors of respondents' reported experiences of flooding in Lagos. However, educational attainment, ethnicity, income, and home ownership were significant predictors of individuals' self-reported experiences of flood events. Individuals who had attained secondary or tertiary education were all less likely to report that they had experienced flood events compared to those who had primary education. Ibos were less likely to have experienced flood events compared to Yorubas probably due to the high number and clustering of Yorubas in Lagos. Individuals who had monthly incomes of up to 160USD were more likely to have experienced flood events compared to individuals in the lowest income group. The two lowest income groups reside in Ijora Badia. This suggests there are heterogeneities in the experience of flooding even within the same community. Also, renters were more likely $(\mathrm{OR}=2.73, p \leq 0.001)$ to report that they had experienced flood events compared to home owners.

Table 4. Multivariate complementary log-log regression model predicting the experience of flooding by coastal communities in Lagos.

\begin{tabular}{|c|c|c|c|c|c|c|}
\hline \multirow[t]{2}{*}{ Variables } & \multicolumn{3}{|c|}{$\begin{array}{l}\text { Model 1: Personal \& Household } \\
\text { Factors }\end{array}$} & \multicolumn{3}{|c|}{$\begin{array}{l}\text { Model 2: Socio-Environmental } \\
\text { Factors }\end{array}$} \\
\hline & OR & (Robust SE) & $95 \%$ CI & OR & (Robust SE) & $95 \% \mathrm{CI}$ \\
\hline \multicolumn{7}{|c|}{ Age (ref: $18-30)$} \\
\hline $31-40$ & 0.87 & $(0.16)$ & $0.61-1.24$ & 1.27 & $(0.39)$ & $0.70-2.33$ \\
\hline $41-65$ & 1.44 & $(0.39)$ & $0.85-2.44$ & 3.11 & $(1.23) * *$ & $1.43-6.75$ \\
\hline \multicolumn{7}{|c|}{ Gender (ref: female) } \\
\hline Male & 1.31 & $(0.21)$ & $0.96-1.78$ & 1.54 & $(0.43)$ & $0.89-2.66$ \\
\hline \multicolumn{7}{|c|}{ Respondent Education (ref: up to primary) } \\
\hline Secondary & 0.58 & $(0.10) * *$ & $0.42-0.81$ & 0.96 & $(0.34)$ & $0.48-1.92$ \\
\hline Tertiary & 0.33 & $(0.07) * * *$ & $0.21-0.51$ & 0.64 & $(0.25)$ & $0.29-1.39$ \\
\hline \multicolumn{7}{|c|}{ Marital Status (ref: Unmarried) } \\
\hline Married & 1.16 & $(0.20)$ & $0.83-1.62$ & 1.82 & $(0.52) *$ & $1.03-3.20$ \\
\hline \multicolumn{7}{|c|}{ Position in Household (ref: Head) } \\
\hline Non-head & 0.74 & $(0.11)$ & $0.55-1.00$ & 0.86 & $(0.24)$ & $0.50-1.49$ \\
\hline \multicolumn{7}{|c|}{ No. People in Household (ref: 1-3) } \\
\hline 4 or 5 & 0.96 & $(0.18)$ & $0.67-1.39$ & 1.39 & $(0.48)$ & $0.71-2.72$ \\
\hline 6 or more & 0.74 & $(0.12)$ & $0.54-1.03$ & 0.75 & $(0.25)$ & $0.39-1.44$ \\
\hline \multicolumn{7}{|c|}{ Ethnicity (ref: Yoruba) } \\
\hline Ibo & 0.27 & $(0.05) * * *$ & $0.20-0.38$ & 0.31 & $(0.08) * * *$ & $0.20-0.50$ \\
\hline Hausa & 0.49 & $(0.21)$ & $0.21-1.15$ & 2.38 & $(1.59)$ & $0.64-8.84$ \\
\hline Other & 0.71 & $(0.26)$ & $0.35-1.44$ & 3.26 & $(1.18) * *$ & $1.61-6.61$ \\
\hline \multicolumn{7}{|c|}{ Occupation (ref: unemployed) } \\
\hline Civil servant & 0.77 & $(0.19)$ & $0.47-1.25$ & 0.92 & $(0.36)$ & $0.43-2.00$ \\
\hline Artisan & 0.75 & $(0.20)$ & $0.45-1.26$ & 0.90 & $(0.38)$ & $0.39-2.07$ \\
\hline self-employed & 1.09 & $(0.25)$ & $0.69-1.71$ & 0.59 & $(0.23)$ & $0.28-1.27$ \\
\hline
\end{tabular}


Table 4. Cont.

\begin{tabular}{|c|c|c|c|c|c|c|}
\hline \multirow[t]{2}{*}{ Variables } & \multicolumn{3}{|c|}{$\begin{array}{c}\text { Model 1: Personal \& Household } \\
\text { Factors }\end{array}$} & \multicolumn{3}{|c|}{$\begin{array}{l}\text { Model 2: Socio-Environmental } \\
\text { Factors }\end{array}$} \\
\hline & OR & (Robust SE) & & OR & (Robust SE) & \\
\hline \multicolumn{7}{|c|}{ Household Income (ref: N5,000-N15,000) } \\
\hline $\mathrm{N} 15,500-\mathrm{N} 25,000$ & 9.48 & $(1.48) * * *$ & $6.99-12.86$ & 20.04 & $(6.67) * * *$ & $10.44-38.48$ \\
\hline $\mathrm{N} 25,500-\mathrm{N} 50,000$ & 1.16 & $(0.22)$ & $0.79-1.68$ & 1.12 & $(0.33)$ & $0.63-2.00$ \\
\hline N50,500- or more & 1.13 & $(0.28)$ & $0.69-1.85$ & 2.44 & $(0.89) *$ & $1.19-5.00$ \\
\hline will rather not say & 0.71 & $(0.11) *$ & $0.52-0.97$ & 1.04 & $(0.28)$ & $0.62-1.75$ \\
\hline \multicolumn{7}{|c|}{ Length of stay in area (ref: less than 5 years) } \\
\hline 5 years or more & 0.54 & $(0.21)$ & $0.25-1.16$ & 0.68 & $(0.37)$ & $0.23-1.98$ \\
\hline \multicolumn{7}{|c|}{ Length of stay in dwelling (ref: less than 5 years) } \\
\hline 5 years or more & 1.88 & $(0.74)$ & $0.87-4.07$ & 1.12 & $(0.62)$ & $0.38-3.30$ \\
\hline \multicolumn{7}{|c|}{ Dwelling ownership (ref: owner) } \\
\hline Renters & 2.73 & $(0.48) * * *$ & $1.94-3.86$ & 2.73 & $(0.76) * * *$ & $1.59-4.70$ \\
\hline \multicolumn{7}{|c|}{ Location (ref: Ijora Badia) } \\
\hline Ajah & & & & 0.22 & $(0.08) * * *$ & $0.11-0.44$ \\
\hline Victoria Island & & & & 0.18 & $(0.07) * * *$ & $0.08-0.39$ \\
\hline \multicolumn{7}{|c|}{ Type of housing (ref: wooden shack) } \\
\hline wooden on stilts & & & & 0.44 & $(0.08) * * *$ & $0.30-0.64$ \\
\hline Concrete & & & & 0.03 & $(0.01) * * *$ & $0.02-0.06$ \\
\hline \multicolumn{7}{|c|}{ Household vulnerability to flood (ref: no) } \\
\hline Yes & & & & 2.43 & $(0.67) * *$ & $1.42-4.19$ \\
\hline Refused to answer & & & & 1.76 & $(1.07)$ & $0.54-5.79$ \\
\hline \multicolumn{7}{|c|}{ Neighbourhood vulnerability to flood (ref: no) } \\
\hline Yes & & & & 3.46 & $(0.93) * * *$ & $2.04-5.85$ \\
\hline Don't know & & & & 4.27 & $(1.91) * *$ & $1.77-10.26$ \\
\hline \multicolumn{7}{|c|}{ Ever received government assistance due to flood (ref: no) } \\
\hline Yes & & & & 0.51 & $(0.14) *$ & $0.30-0.87$ \\
\hline \multicolumn{7}{|c|}{ Access to social housing (ref: no) } \\
\hline Yes & & & & 1.46 & $(0.47)$ & $0.77-2.75$ \\
\hline \multicolumn{7}{|c|}{ Access to water services (ref: poor) } \\
\hline good water access & & & & 0.91 & $(0.27)$ & $0.51-1.61$ \\
\hline \multicolumn{7}{|c|}{ Distance to nearest healthcare facility (ref: $5 \mathrm{~km}$ or more) } \\
\hline Less than $5 \mathrm{~km}$ & & & & 0.91 & $(0.22)$ & $0.56-1.47$ \\
\hline
\end{tabular}

In model 2, age, gender, marital status and household composition became statistically significant when socio-environmental factors were accounted for. However, length of stay in the neighbourhood was still not a significant predictor of experience of flood events by residents. After controlling for socio-environmental factors, education was no longer a predictor of residents' reported experiences of flooding. The excess odds for home ownership as a predictor of experience of flood events remained unchanged. As shown in the model, residents of Ajah and Victoria Island were less likely to have experienced flooding compared to their counterparts in Ijora Badia. Also, individuals who lived in wooden stilts and concrete houses were less likely to have experienced flooding compared to their 
counterparts who resided in wooden shacks on ground. Interestingly, individuals who had received government assistance were less likely than not to have experienced flooding. Such social assistance may have the effect of reducing losses experienced during flooding thereby accounting for recipients' limited report about the experience of flood. An alternate explanation could be that social assistance on flooding in Lagos is often misdirected to aid certain groups who may not necessarily be the most vulnerable.

\section{Discussion}

The central aim of this research was to understand and quantify the personal and socio-environmental determinants of the experience of flood events, ocean surges and changing rainfall patterns by residents in Lagos, Nigeria. An analysis of compositional and contextual factors has shown that there are areas (communities) where high levels of flooding tend to be clustered and that this is not fully explained by the individual characteristics of the people of whom the community is composed. For instance, on the basis of geographical location alone, one would expect higher levels of vulnerability and higher perception in Victoria Island due to proximity to the ocean and lagoon. However, our findings indicate that Ijora Badia is much more vulnerable because of the nature of the built environment which is characterized by the lack of drainage systems, substandard housing quality and poor waste disposal practices. These findings are consistent with the work of [55]. This study, thus, underscores the importance and complex nature of the interaction between individual and socio-environmental determinants in shaping climate change experiences, risk of hazard, and vulnerability of individuals and households across neighbourhoods and communities. In some cases, buildings were located in hazard prone areas within the three communities. In fact, every two out of three respondents indicated that their current dwelling was prone to flooding and every four out of five respondents indicated that their residential neighborhood was prone to flooding. This is probably because of the topography of the city and the quality of housing in the neighbourhoods. We observed differential experience of flooding by dwelling ownership. Most homeowners live on upper levels of storey buildings while renters who tend to experience more flooding occupy the lower sections which may be susceptible to flooding. A disproportionate number of such cases were in the poorest community; that is, Ijora Badia. Unexpectedly, individuals who had received government assistance due to flooding were less likely to report that they had experienced flood events, thus suggesting politically-motivated disaster relief. It appears that government assistance reduces perceptions of vulnerability which in essence demonstrates the complex interplay of economic conditions, electoral politics, and moral hazard in shaping the ways in which politicians allocate, or fail to allocate, resources in light of natural disasters [59]. Clearly, this issue shapes people's perception and experience of disaster impacts.

Since residents in Ijora Badia were often victims of forcible evictions in connection with development projects [55], one can deduce that broader structural issues and development policies also play a major role in increasing vulnerability to climate and other environmental hazards. This focus on the social production of vulnerability points to economic and political determinants of unequal exposure to climatic risks including structural barriers preventing people from living safer lives [60]. This is a direct response to blame-the-victim lifestyle notions, which draw attention to individual responsibility to choose socalled less risky environments in order to cope better with climatic risk [61]. 
By focusing on the relationship between the social environment and residents' perception of flooding, ocean surges and rainfall patterns, we make contributions to a nuanced understanding of three distinct but closely related social phenomena. First is that neighbourhood characteristics are more than the sum of the individuals living in them [62]. For this reason, neighbourhoods exhibit a patterned regularity of vulnerability rates over time even though individuals come and go. Second, there are features of neighbourhoods that strengthen or weaken social support and social cohesion [55], and these have important implications for the wellbeing of residents in those neighbourhoods [63]. Third, as evidenced in this study, the social characteristics of a neighbourhood are not simply a result of geographic location but rather influenced by socioeconomic status of residents, available public services and infrastructure, social behaviour, and governance policy. In essence, the vulnerability associated with the experience of climate events at the individual and population levels are shaped by the interaction of multifaceted factors which have both local and broader structural origins. Perhaps, the most important contributory factors to vulnerability at the population level result from substantial changes in society linked to population increases, urbanization, economic fluctuations and infrastructural deficits which alter the adaptive capacity of communities [28,64]. For instance, population growth in Lagos underpins the use of marginal lands and wetland areas as human settlements [36,64]. These societal changes create fragile environments which foster physical vulnerability at the individual, household and community levels.

A dynamic interaction between individual income, housing quality, and length of stay in dwelling, community characteristics, and broader structural barriers in producing vulnerability were evident in this study. Residents in Ajah were more likely to have experienced changes in rainfall patterns compared to residents in Ijora Badia; the poorest community, this perhaps may be due to patterns of convectional rainfall in Lagos. Also, individuals in Ajah and Victoria Island (the richest community) were more likely to have experienced ocean surges compared to residents of Ijora Badia, because of their proximity to the Atlantic Ocean. Individuals who lived for more than 5 years in their current dwelling were less likely to report having experienced changes in rainfall patterns compared to their counterparts who lived in their dwelling for less than 5 years. We suggest that residents who have lived longer in their current home were accustomed to the changes and hardly problematized the changes in rainfall patterns unlike their more recent counterparts.

We found that neither the compositional nor contextual factors alone were sufficient to completely explain residents' experiences of a particular climatic event. In fact, both dimensions simultaneously contribute to the explanation, although not proportionally so. This was evidenced in the higher odds when socio-environmental factors were considered in addition to individual-level factors in explaining the experiences of climatic events by residents. Regarding residents' experiences of changing rainfall patterns and ocean surges; individual and socio-environmental factors were not different in terms of strength of prediction. However, in terms of the residents' experience of flood events, we found socio-environmental factors were stronger predictors than individual-level variables. It is reported elsewhere that individual-level variables interact with environmental variables in predicting outcomes such as vulnerability $[61,65,66]$. In certain studies, after individual economic variables were added to the models, environmental characteristics were no longer predictive of the outcome $[67,68]$. Our study predicting residents' climate experiences, however, is inconsistent with this observation, as the socio-environmental factors increased the excess odds of the experiences of climate hazards. 
A number of socio-environmental factors remain salient for poor communities when dealing with climatic events. Some respondents $(63 \%)$ indicated that they had to walk more than $5 \mathrm{~km}$ to access public healthcare services. A disproportionate number of such individuals were resident in the poorest community of Ijora Badia. Furthermore, those who indicated poor access to water services were densely populated in the same area. It is argued that the risks associated with good or bad health are not evenly distributed throughout a population which is defined by geographical boundaries or some other common characteristic, for example, neighbourhood environment [69-71]. Such health-related risks feed into inequalities and vulnerabilities, which eventually manifest differentially in various neighbourhoods in a community [60]. This brings to the fore the need to examine the role of place in hazard vulnerability research [50]. It presents the difficulty of disentangling the individual-level (compositional) and neighbourhood/community level (contextual) influences on outcomes of climate-related events. As argued by MacIntyre et al. [72] in the context of variations in health outcomes, it is possible that variations in climate change perceptions may also be due in large part to compositional effects, whereby particular types of people who are at a high risk for disasters are found to be clustered within particular places. For instance, in this study, we found that a high proportion of low income earners were clustered in Ijora Badia. Also, variation in climate-related outcomes (e.g., experience of flood events) may, in part, be due to a particular characteristic or feature of the social (e.g., poverty and low coping capacity) or physical and built environment (degraded/water logged land and poor housing) that is putting a population at a higher risk of impacts. For instance, we found that a disproportionately higher number of residents in Ijora Badia live in wooden shacks compared to Victoria Island (the richest community) where residents live in concrete storey buildings. More so, Ijora Badia respondents exhibit a high level of overall vulnerability resulting from their compositional and contextual circumstances. These findings suggest that poor areas may have a leveling effect; that is, life in a poverty-stricken and environmentally degraded area may overwhelm other important factors. For example, ethnicity and personal income were not as significant in Ijora Badia as they were in more affluent areas. This observation is consistent with the findings of Crandall and Weber [73], Chowdhury et al. [74], and Yen and Kaplan [75].

Various possible reasons could also be posited for the relatively strong differences in exposure to flood events between more and less deprived people living in relatively affluent neighbourhoods such as Victoria Island and Ajah. The effect may be a statistical one, resulting from more extreme differences in wealth between individuals in more affluent neighbourhoods, so that stronger socio-economic inequality is reflected in clearer differences in exposure to flooding and ocean surges. One possibility is that individuals with low deprivation scores in more affluent neighbourhoods are in fact affluent and that the deprivation score is not adequately representing the difference between the very rich individuals and deprived people. Another effect may be a socioeconomic one, in that the impact of a given level of poverty is greater for an individual living in a generally more affluent neighbourhood; perhaps because a sense of relative deprivation is more acute and has a more severe impact on psychological state of the individual and because community support for deprived minorities is less in affluent neighbourhoods, or perhaps because the cost of achieving a reasonable standard of living is greater so that the poor suffer particularly marked material hardship in predominantly wealthy neighbourhoods. 


\section{Conclusions}

The study presented in this paper fundamentally examines whether perceptions of exposure to climatic events and variability can be linked to contextual variables; that is, the characteristics of a residential neighborhood or place (e.g., the degree of segregation, housing quality, social support, or environmental factors for specific spatial areas) as well as population compositional variables, that is, characteristics of the population living in a specific area (e.g., income, ethnicity, or educational level for a specific population). In doing so, our analyses have not only identified characteristics of specific populations at risk, but we have also outlined the geographic areas where disparities occur. This study has shown that regardless of their individual characteristics, residents in more socio-environmentally disadvantaged neighbourhoods report having experienced more flood events. We hypothesize a number of mechanisms by which socio-environmental factors might influence differential experience of climatic events for residents in disadvantaged neighbourhoods. First, the biophysical characteristics of the environment (if it is low-lying and prone to water-logging) may be important. Second, the effect of the domestic policy environment and its connection with housing provision in the local area may also have an impact. For instance, the physical design (wooden shack, wooden on stilts and concrete) and housing conditions (availability of sanitation, refuse disposal, and on-site drainage) may render poorer residents vulnerable to flood events. Third, the provision of services including water, health care, and educational status as well as socio-cultural features of neighbourhoods and the reputation of an area which may affect adaptive capacity are important [55]. Our findings are therefore pertinent to community disaster-risk reduction and climate change adaptation, which aim to reduce inequalities in climate exposures and risks by improving the urban environment and socio-environmental conditions of the poorest members of society. In areas where vulnerability levels are generally high, it may be necessary to take action at the scale of whole communities, as well as for deprived individuals within those communities. Our findings indicate that the most significant factors that culminate in vulnerability are nested and relate to individual characteristics, place-based elements, and broader socio-environmental, economic and political factors. High levels of poverty, marginalization and politically-motivated disaster relief in communities determine differential vulnerability between people in different geographic regions. This, in turn, shapes individual perceptions of vulnerability to climate-related hazards. Addressing these factors requires redesigning the social and structural relationships in urban societies to allow for greater inclusion and support for low-income populations living in environmentally precarious areas. Most dominant disaster risk reduction strategies over time have proven to be less effective because they do not take into account the perceptions and situations of individuals at risk from climate-related hazards and do not address the daily realities of people and their socio-environmental contexts. This study deviates from the norm by accounting for perceptions as well as experiences of people, and it concludes that certain sub-populations, as well as residential clusters or "hot spots" in Lagos, require a greater voice in urban planning and management and greater institutional support and infrastructural investments that can aid disaster risk reduction and bolster adaptation to the changing climate and its extremities. 


\section{Acknowledgments}

We acknowledge research funding from the Coastal Cities at Risk (CCaR) project, which is part of the International Research Initiative on Adaptation to Climate Change (IRIACC).

\section{Author Contributions}

Idowu Ajibade and Gordon McBean were involved in the conception and design of the study. Idowu Ajibade was involved in acquisition of data. Idowu Ajibade, Frederick Ato Armah, Vincent Kuuire, Isaac Luginaah and Gordon McBean were involved in analysis and interpretation of data. Idowu Ajibade, Frederick Ato Armah, Vincent Kuuire, Isaac Luginaah and Gordon McBean were involved in drafting the article or revising it critically for important intellectual content. Idowu Ajibade, Frederick Ato Armah, Vincent Kuuire, Isaac Luginaah and Gordon McBean were involved in final approval of the version to be published.

\section{Conflicts of Interest}

The authors declare no conflicts of interest.

\section{References}

1. Benson, C.; Clay, E.J. Understanding the Economic and Financial Impacts of Natural Disasters; Disaster Risk Management Series No. 4; World Bank Publications: Washington, DC, USA, 2004.

2. Eriksen, S.H.; Brown, K.; Kelly, P.M. The dynamics of vulnerability: Locating coping strategies in Kenya and Tanzania. Geogr. J. 2005, 171, 287-305.

3. Intergovernmental Panel on Climate Change (IPCC). Summary for policymakers. In Managing the Risks of Extreme Events and Disasters to Advance Climate Change Adaptation; A Special Report of Working Groups I and II of the Intergovernmental Panel on Climate Change; Cambridge University Press: Cambridge, UK; New York, NY, USA, 2012.

4. Klein, R.J.T.; Nicholls, R.J.; Thomalla, F. The resilience of coastal megacities to weather-related hazards. In Building Safer Cities: The Future of Disaster Risk; Kreimer, A., Arnold, M., Carlin, A., Eds.; The World Bank Disaster Management Facility: Washington, DC, USA, 2002; pp. 101-120.

5. Moreno, E.L.; Oyeyinka, O.; Mboup, G.; Sampath, P.; Zanetta, C.; Kothari, M.; Shivani C.; Williams, C. State of the World's Cities 2010/2011-Cities for All: Bridging the Urban Divide; Earthscan: London, UK, 2010.

6. Thomson, M.C.; Doblas-Reyes, F.J.; Mason, S.J.; Hagedorn, R.; Connor, S.J.; Phindela, T.; Morse, A.P.; Palmer, T.N. Malaria early warnings based on seasonal climate forecasts from multi-model ensembles. Nature 2006, 439, 576-579.

7. Hewawasam, I. Managing the Marine and Coastal Environment of Sub-Saharan Africa: Strategic Directions for Sustainable Development; World Bank: Washington, DC, USA, 2002; p. 57.

8. Nicholls, R.J. Coastal flooding and wetland loss in the 21 st century: Changes under the SRES climate and socio-economic scenarios. Glob. Environ. Chang. 2004, 14, 69-86.

9. McMichael, A.J.; Woodruff, R.E.; Hales, S. Climate change and human health: Present and future risks. Lancet 2006, 367, 859-869. 
10. Few, R.; Ahern, M.; Matthies, F.; Kovats, S. Floods, Health and Climate Change: A Strategic Review; Working Paper 63; Tyndall Centre for Climate Change Research, University of East Anglia: Norwich, UK, 2004; p. 138.

11. Boko, M.; Niang, I.; Nyong, A.; Vogel, C.; Githeko, A.; Medany, M.; Osman-Elasha, B.; Tabo, R.; Yanda, P. Impacts, adaptation and vulnerability; Contribution of Working Group II to the Fourth Assessment Report of the Intergovernmental Panel on Climate Change; Parry, M.L., Canziani, O.F., Palutikof, J.P., Van der Linden, P.J., Hanson, C.E., Eds.; Cambridge University Press: Cambridge, UK, 2007; pp. 433-467.

12. Piguet, E. Linking climate change, environmental degradation and migration: A methodological overview. Wiley Interdiscip. Rev. Clim. Chang. 2010, 1, 517-524.

13. Odjugo P.A.O. Quantifying the cost of climate change impact in Nigeria: Emphasis on wind and rainstorms. J. Hum. Ecol. 2009, 28, 93-101.

14. Coe, M.; Foley, J.A. Human and natural impacts on the water resources of the Lake Chad Basin. J. Geophys. Res. 2001, 106, 3349-3356.

15. Adejuwon, J.O. Food crop production in Nigeria. II: Potential effects of climate change. Clim. Res. 2006, 32, 229-245.

16. Odjugo, P.A.O. General overview of climate change impacts in Nigeria. J. Hum. Ecol. 2010, 29, $47-55$.

17. Odjugo, P.A.O. An analysis of rainfall pattern in Nigeria. Glob. J. Environ. Sci. 2005, 4, 139-145.

18. Wheeler, D. Quantifying Vulnerability to Climate Change: Implications for Adaptation Assistance; Center for Global Development: Washington, DC, USA, 2011.

19. Treichel, V. Putting Nigeria to Work: A Strategy for Employment and Growth; World Bank: Washington, DC, USA, 2010.

20. UK Department of International Development (DFID/ERM). Impact of Climate Change on Nigeria's Economy; DFID: Abuja, Nigeria, 2009.

21. Blennow, K.; Persson, J.; Tome, M.; Hanewinkel, M. Climate change: Believing and seeing implies adapting. PLoS One 2012, 7, e50182.

22. Leiserowitz, A. Climate change risk perception and policy preferences: the role of affect, imagery, and values. Clim. Chang. 2006, 77, 45-72.

23. Blennow, K.; Persson, J. Climate change: Motivation for taking measure to adapt. Glob. Environ. Chang. 2009, 19, 100-104.

24. Weber, E. What shapes perceptions of climate change? Wiley Interdiscip. Rev. Clim. Chang. 2010, $1,332-342$.

25. Spence, A.; Poortinga, W.; Butler, C.; Pidgeon, N.F. Perceptions of climate change and willingness to save energy related to flood experience. Nat. Clim. Chang. 2011, 1, 46-49.

26. Weber, E. Experience-based and description-based perceptions of long term risk: Why global warming does not scare us (yet). Clim. Chang. 2006, 77, 103-120.

27. Leiserowitz, A.; Maibach, E.; Roser-Renouf, C.; Hmielowski, J.D. Extreme Weather, Climate \& Preparedness in the American Mind. Available online: http:// environment.yale.edu/climate/files/ Extreme-Weather-Climate-Preparedness.pdf. (accessed on 28 August 2013).

28. Costello, A.; Abbas, M.; Allen, A.; Ball, S.; Bell, S.; Bellamy, R.; Patterson, C. Managing the health effects of climate change. Lancet 2009, 373, 1693-1733. 
29. Weber, E.U.; Stern, P.C. Public understanding of climate change in the United States. Amer. Psych. 2011, 66, 315-328.

30. Daw, T.M.; Robinson, J.A.N.; Graham, N.A. Perceptions of trends in Seychelles artisanal trap fisheries: Comparing catch monitoring, underwater visual census and fishers' knowledge. Environ. Conserv. 2011, 38, 75-88.

31. MacIntyre, S.; Ellaway, A.; Cummins, S. Place effects on health: How can we conceptualise, operationalise and measure them? Soc. Sci. Med. 2002, 55, 125-139.

32. Armitage, D.R.; Plummer, R.; Berkes, F.; Arthur, R.I.; Charles, A.T.; Davidson-Hunt, I.J.; Wollenberg, E.K. Adaptive co-management for social-ecological complexity. Front. Ecol. Environ. 2008, 7, 95-102.

33. Tschakert, P.; Dietrich, K.A. Anticipatory learning for climate change adaptation and resilience. Ecol. Soc. 2010, 15, 11-33.

34. Crate, S.A.; Nuttall, M.; Eds. Anthropology and Climate Change: From Encounters to Actions; Left Coast Press: Walnut Creek, CA, USA, 2009.

35. Gifford, R. The dragons of inaction: Psychological barriers that limit climate change mitigation and adaptation. Am. Psychol. 2011, 66, doi:10.1037/a0023566.

36. Braimoh, A.K.; Onishi, T. Spatial determinants of urban land use change in Lagos, Nigeria. Land Use Policy 2007, 24, 502-515.

37. Hahn, M.B.; Riederer, A.M.; Foster, S.O. The livelihood vulnerability index: A pragmatic approach to assessing risks from climate variability and change-A case study in Mozambique. Glob. Environ. Chang. 2009, 19, 74-88.

38. Barrios, S.; Bertinelli, L.; Strobl, E. Climatic change and rural-urban migration: The case of sub-Saharan Africa. J. Urban Econ. 2006, 60, 357-371.

39. Kuruppu, N.; Liverman, D. Mental preparation for climate adaptation: The role of cognition and culture in enhancing adaptive capacity of water management in Kiribati. Glob. Environ. Chang. 2011, 21, 657-669.

40. Bryan, E.; Ringler, C.; Okoba, B.; Roncoli, C.; Silvestri, S.; Herrero, M. Adapting agriculture to climate change in Kenya: Household strategies and determinants. J. Environ. Manag. 2013, 114, $26-35$.

41. Wolf, J.; Adger, W.N.; Lorenzoni, I.; Abrahamson, V.; Raine, R. Social capital, individual responses to heat waves and climate change adaptation: An empirical study of two UK cities. Glob. Environ. Chang. 2010, 20, 44-52.

42. Adger, N. Vulnerability. Glob. Environ. Chang. 2006, 16, 268-281.

43. Cutter, S. Vulnerability to environmental hazard. Prog. Hum. Geogr. 1996, 20, 529-539.

44. Wisner, B.; Blaikie, P.; Cannon, T.; Davis, I. At Risk: Natural Hazards, People's Vulnerability and Disasters, 2nd ed.; Routledge: London, UK, 2004.

45. Kelly, P.M.; Adger, N. Theory and practice in assessing vulnerability to climate change and facilitating adaptation. Clim. Chang. 2000, 47, 325-352.

46. O’Brien, K.L.; Leichenko, R.; Kelkar, U.; Venema, H.; Aandahl, G.; Tompkins, H.; West, J. Mapping vulnerability to multiple stressors: Climate change and globalization in India. Glob. Environ. Chang. 2004, 14, 303-313. 
47. Sen, A. Poverty and Famines: An Essay on Entitlement and Deprivation; Clarendon: Oxford, UK, 1981.

48. Watt, M.; Bohle, H. Hunger, famine and the space of vulnerability. GeoJournal 1993, 30, $117-125$.

49. Blaikie, P.; Brookfield, H. Land Degradation and Society; Methuen: London, UK, 1987.

50. Lankao, P.; Qin, H. Conceptualising urban vulnerability to global climate and environmental change. Curr. Opin. Glob. Environ. Sustain. 2011, 3, 142-149.

51. Cutter, S.; Emrich, C. Moral hazard, social catastrophe: The changing face of vulnerability along the coasts. Ann. Am. Assoc. Polit. Soc. Sci. 2006, 604, 102-112.

52. Awosika, F.; French, T.; Nicholls, R.; Ibe, E. Impacts of sea level rise on Nigeria. In Proceedings of the 1992 IPCC Symposium: The Rising Challenge of the Sea, Margarita, Venezuela, 14-19 March 1992.

53. Rosenzweig, C.; Solecki, W.D.; Hammer, S.A. Climate Change and Cities: First Assessment report of the Urban Climate Change Research Network; Cambridge University Press: Cmbridge, UK, 2011.

54. The State of African Cities: Re-Imaging Sustainable Urban Transitions. Available online: http://unhabitat.org/the-state-of-african-cities-2014/ (accessed on 15 June 2014).

55. Pol, L.G.; Thomas, R.K. Population size, distribution and concentration. In The Demography of Health and Healthcare; Springer: Dordrecht, The Netherlands, 2013; pp. 37-63.

56. Awosika, L.F.; Dublin-Green, C.O.; Folorunsho, R.; Adekoya, E.A.; Adekanmbi, M.A.; Jim-Saiki, J. Study of Main Drainage Channels of Victoria and Ikoyi Islands in Lagos Nigeria and Their Response to Tidal and Sea Level Changes; CSI-UNESCO Special Report; United Nations: New York, NY, USA, 2000.

57. Okusipe, O.M. Lagos Lagoon Coastal Profile: Information Database for Planning Theory; Lagos State Environment Report; Lagos State Ministry of Environment: Lagos, Nigeria, 2004.

58. Brooks, N.; Adger, W.N.; Kelly, P M. The determinants of vulnerability and adaptive capacity. Glob. Environ. Chang. 2005, 15, 151-163.

59. Ajibade, I.; McBean, G. Climate extremes and housing rights: A political ecology of impacts, early warning and adaptation constraints in slum communities. Geoforum 2014, 55, 76-86.

60. Cohen, C.; Werker, E.D. The political economy of "natural" disasters. J. Confl. Resolut. 2008, 52, 795-819.

61. Jerrett, M.; Gale, S.; Kontgis, C. An environmental health geography of risk. In A Companion to Health and Medical Geography; Brown, T., McLafferty, S., Moon, G., Eds.; Wiley-Blackwell: Chichester, UK, 2010; pp. 418-445.

62. Curtis, S.; Oven, K. Geographies of health and climate change. Prog. Hum. Geogr. 2012, 36, 654-666.

63. Atkinson, R.; Kintrea, K. Owner-occupation, social mix and neighbourhood impacts. Policy Polit. 2000, 28, 93-108.

64. Atkinson, R.; Kintrea, K. Disentangling area effects: Evidence from deprived and non-deprived neighbourhoods. Urban Stud. 2001, 38, 2277-2298.

65. Yen, I.H.; Kaplan, G.A. Poverty area residence and changes in physical activity level: Evidence from the Alameda County Study. Am. J. Public Health 1998, 88, 1709-1712. 
66. Ebi, K.L.; Lewis, N.D.; Corvalan, C. Climate variability and change and their potential health effects in small island states: Information for adaptation planning in the health sector. Environ. Health Perspect. 2006, 114, 1957-1963.

67. Haines, A.; Kovats, R.S.; Campbell-Lendrum, D.; Corvalan, C. Climate change and human health: Impacts, vulnerability, and mitigation. Lancet 2006, 367, 2101-2109.

68. Waitzman, N.J.; Smith, K.R. Phantom of the area: poverty residence and mortality in the U.S. Am. J. Public Health 1998, 88, 973-976

69. Ellen, I.G.; Mijanovich, T.; Dillman, K.N. Neighborhood effects on health: Exploring the links and assessing the evidence. J. Urban Aff. 2003, 23, 391-408.

70. Kawachi, I.; Subramanian, S.V.; Almeida-Filho, N. A glossary for health inequalities. J. Epidemiol. Community Health 2002, 56, 647-652.

71. Schulz, A.; Northridge, M.E. Social determinants of health: Implications for environmental health promotion. Health Educ. Behav. 2004, 31, 455-471.

72. Williams, D.R. Race, socioeconomic status, and health the added effects of racism and discrimination. Ann. N. Y. Acad. Sci. 2006, 896, 173-188.

73. Barredo, J.I.; Demicheli, L.; Lavalle, C.; Kasanko, M.; McCormick, N. Modelling future urban scenarios in developing countries: An application case study in Lagos, Nigeria. Environ. Plan. B-Plan. Des. 2004, 31, 65-84.

74. Crandall, M.S.; Weber, B.A. Local social and economic conditions, spatial concentrations of poverty, and poverty dynamics. Am. J. Agric. Econ. 2004, 86, 1276-1281.

75. Chowdhury, M.J.A.; Ghosh, D.; Wright, R.E. The impact of micro-credit on poverty: Evidence from Bangladesh. Prog. Dev. Stud. 2005, 5, 298-309.

(C) 2014 by the authors; licensee MDPI, Basel, Switzerland. This article is an open access article distributed under the terms and conditions of the Creative Commons Attribution license (http://creativecommons.org/licenses/by/4.0/). 